\title{
Gilberto Freyre: um vitoriano dos trópicos
}

Afrânio Garcia

$\mathbb{P}^{\circ}$

OUCOS LIVROS contribuíram tanto pa-

ra a renovação das categorias de pensamento sobre o Brasil como Casa grande \& senzala, publicado em 1933 no Rio de Janeiro e traduzido em 1952 para o francês por Roger Bastide, com prefácio de Lucien Febvre, após a edição inglesa (1946). A valorização da mestiçagem como característica nacional contrasta fortemente com a longa série de escritos de autores brasileiros desde 1870, associando mestiçagem e degenerescência da população, concebida em decorrência disso como incapaz de alcançar a civilização. Desde o prefácio da primeira edição Gilberto Freyre atribuía a originalidade de seu ponto de vista aos estudos feitos na Universidade de Colúmbia, sob a direção de Franz Boas:

O professor Franz Boas é a figura de mestre de que me ficou até hoje maior impressão. Conheci-o nos meus primeiros dias em Colúmbia. Creio que nenhum estudante russo, dos românticos, do século XIX, preocupou-se mais intensamente pelos destinos da Rússia do que eu pelos do Brasil na fase em que conheci Boas [...] Foi o estudo de antropologia sob a orientação do professor Boas que primeiro me revelou o negro e o mulato no seu justo valor - separados dos traços de raça os efeitos do ambiente ou da experiência cultural. Aprendi a considerar fundamental a diferença entre raça e cultura; a discriminar entre os efeitos de relações puramente genéticas e os de influências sociais, de herança cultural e de meio. Neste critério de diferenciação fundamental entre raça e cultura assenta todo o plano deste ensaio. (Freyre, 2005, p.31)
A contribuição de Gilberto Freyre, porém, não se limita a combater a vergonha de si dos brasileiros como povo de mestiços por meio da reafirmação da oposição entre raça e cultura; seu livro procura estudar a matriz social da mestiçagem no espaço brasileiro desde os inícios da colonização portuguesa:

No Brasil, as relações entre os brancos e as raças de cor foram desde a primeira metade do século XVI condicionadas, de um lado pelo sistema de produção econômica - a monocultura latifundiária; do outro, pela escassez de mulheres brancas, entre os conquistadores. $\mathrm{O}$ açúcar não só abafou as indústrias democráticas de pau-brasil e de peles, como esterilizou a terra, em uma grande extensão em volta aos engenhos de cana, para os esforços de policultura e de pecuária. E exigiu uma enorme massa de escravos. A criação de gado, com possibilidade de vida democrática, deslocou-se para os sertões. Na zona agrária desenvolveuse, com a monocultura absorvente, uma sociedade semi feudal - uma minoria de brancos e brancarões dominando patriarcais, polígamos, do alto das casas-grandes de pedra e cal, não só os escravos criados aos magotes nas senzalas como os lavradores de partido, os agregados, moradores de casas de taipa e de palhas vassalos das casasgrande em todo o rigor da expressão. (ibidem, p.32-3)

O poder dos senhores brancos e polígamos inscreveu-se no espaço das imensas plantações de culturas tropicais mediante a oposição casa grande/senzala e também nos corpos dos indivíduos, pois toda mestiçagem tornou-se um indício 
de uma relação mais ou menos antiga, mais ou menos durável, entre um senhor branco e as mulheres negras, ameríndias ou mestiças. O elo estável com a esposa branca, sancionado pelo casamento católico e a residência na casa do senhor, não impedia de modo algum a multiplicidade de uniões contratadas pelos patriarcas, temporárias ou permanentes, na origem de uma vasta progenitura reivindicada pelos homens como atestado de sua virilidade. O livro de Gilberto Freyre, sem dúvida alguma, distingue-se pelo espaço restrito da análise da economia ou das relações políticas sob o regime escravagista e pelo privilégio concedido à sexualidade. Como as relações familiares eram regradas pela moral católica, o objeto de estudo de Freyre não são as práticas de alianças e de filiações legítimas, mas sim os efeitos múltiplos da poligamia dos patriarcas brancos sobre "a vida íntima dos Brasileiros". Em razão disso Lucien Febvre, em seu prefácio, enfatizava que "compreendemos então, por que, neste livro corajoso de Gilberto Freyre, a questão sexual ocupa um lugar tão destacado. É que ela está situada no âmago mesmo do tema - que não é 'a história do Brasil, do desembarque fortuito de Cabral ao fim da hegemonia açucareira' - mas sim o estudo das complexas relações entre três grandes massas humanas" (Freyre, 1974, p.16).

Um dos maiores méritos de Maria Lucia Pallares-Burke foi o de refazer o itinerário dos estudos e viagens internacionais de Gilberto Freyre, aos Estados Unidos e à Europa, para analisar em que medida as questões examinadas em Casa grande \& senzala relacionavam-se à apropriação de leituras e conferências freqüentadas pelo seu autor ao longo de extensos períodos no exterior. Em vez de fazer mais um comentário sobre a relação atribuída a Gilberto Freyre e Franz Boas, Pallares-Burke procede a uma análise detalhada dos estudos cumpridos nos Estados Unidos, dos programas de cursos e leituras realizadas, das notas e diplomas obtidos, dos laços de amizade estabelecidos que permitiram a efetivação de seus projetos intelectuais. Obrigando-se a seguir uma ordem cronológica estrita, para evitar a armadilha de somente enxergar na trajetória de Freyre os passos que conduzem à sua obra-prima, Pallares-Burke pôde destruir vários mitos sobre a formação intelectual de Freyre, inclusive aqueles que o próprio escritor e seus próximos fizeram questão de propagar, e pôde reconstituir de uma forma sólida sua trajetória intelectual, tanto no Brasil como nos Estados Unidos e na Europa. Durante nove anos, ela examinou os arquivos de Freyre no Recife, especialmente a correspondência, os diários e cadernos de anotações, incluindo todos os traços de sua atividade como leitor, inscritos nos livros de sua biblioteca; além disso, ela viajou aos Estados Unidos para compreender a formação universitária de Freyre, reconstituindo a oferta de cursos, os programas de leituras obrigatórias, os exames e as notas do percurso do estudante, os professores e colegas com quem ele tinha estabelecido relações, os debates intelectuais e políticos dessa época e a oferta cultural extra-universitária. Esse trabalho enorme permitiu-lhe compreender o percurso universitário de Gilberto Freyre de uma forma radicalmente nova, incluindo a relação com os ensinamentos de Franz Boas na Universidade de Colúmbia.

Nascido em uma família abastada e católica do Recife em 1900, Gilberto Freyre estudou no liceu batista e nor- 
te-americano situado nessa capital do Nordeste, tendo se convertido ao protestantismo aos dezesseis anos. A guerra na Europa e suas convicções religiosas constituíram os principais fatores de sua partida para a Universidade de Baylor, na cidade de Waco no Texas, assim como de seu irmão mais velho, Ulisses, que o precedeu. Situada no coração da região conhecida como "Bible Belt" numa cidade freqüentemente associada à imagem de "Roma batista", a universidade estava fortemente impregnada de puritanismo religioso. Sendo o único estudante estrangeiro nessa instituição entre 867 colegas, em outubro de 1918, Freyre ligou-se ao diretor do Departamento de Inglês, o professor Andrew Armstrong, que parecia admirá-lo e prodigar-lhe sinais de afeto. Gilberto Freyre consagrou-se aos estudos literários: das 22 disciplinas examinadas, nove eram oferecidas pelo Departamento de Inglês, e somente cinco diziam respeito à sociologia. Se os talentos literários de Freyre foram objeto de menção pelos seus professores, suas anotações pessoais e suas cartas aos amigos próximos demonstram que ele rapidamente percebeu que seu diploma em "Artes" não lhe abriria as portas de uma carreira literária ou acadêmica nos Estados Unidos. Além disso, o jovem nordestino não se adaptou bem aos rigores da ética puritana e a proximidade com o professor Amstrong não impediu que ele sentisse uma franca hostilidade à Universidade de Baylor, descrita mais tarde por Freyre como obtusa e provinciana.

A passagem pela Universidade de Colúmbia permitiu que Freyre vivesse no ambiente cosmopolita de Nova York e orientasse sua trajetória intelectual na direção das ciências sociais. Pallares-
Burke analisou minuciosamente o dossiê do jovem brasileiro e esclareceu a orientação de seus estudos de doutoramento: seu orientador foi William R. Shepherd (1871-1934), especialista na história da América do Sul. As disciplinas escolhidas mostram o investimento prioritário no domínio da História, objeto de seis dos quatorze cursos freqüentados, os restantes dividindo-se em "Lei Pública" (dois), Sociologia (dois), Antropologia (dois), Inglês (um) e Belas-Artes (um) (Pallares-Burke, 2005, p.71-3). Uma das disciplinas de Antropologia, com efeito, foi proposta por Franz Boas, já célebre pelo seu combate contra o racismo nos Estados Unidos e pela demonstração da importância do meio cultural para a evolução das características biológicas das populações imigrantes, mas não há nenhum traço de uma ligação mais direta entre o jovem nordestino e o eminente alemão. Os escritos dessa época de Freyre afastam-se sensivelmente das principais teses defendidas por esse antropólogo. Sua correspondência corrobora a idéia de que no início ele visava a uma tese de Ph.D. em ciência políticas, mas que abandonou seus planos originais em prol de um mestrado em ciências sociais, para grande decepção do professor Amstrong de Baylor e de seu conselheiro e amigo, o diplomata e historiador Oliveira Lima. A intensidade e a dificuldade dos estudos seguidos parecem estar na origem do encurtamento de sua permanência em Nova York, pois ele mostrou dispor de suficientes recursos financeiros para viajar quase um ano pela Europa. As leituras analisadas por Pallares-Burke mostram que Freyre buscou prover-se de uma cultura histórica aprofundada, na esperança talvez de poder seguir posteriormente uma carrei- 
ra acadêmica nos Estados Unidos, pretensões abandonadas no momento da decisão de não enfrentar os desafios do doutorado. Pallares-Burke assinala que Freyre modificou e aumentou sensivelmente a dissertação de mestrado quando ele a republicou nos anos 1950 com o subtítulo "o embrião de Casa grande \& senzala". A análise da versão original sugere, porém, que "a tese de 1922 estava muito distante de Casa grande ésenzala e muito próxima das opiniões então prevalecentes sobre raça e as benesses da eugenia nas questões raciais" (Pallares-Burke, 2005, p.266). Freyre refere-se mesmo a um "melhoramento da raça escrava" (an improved slave breed), pois freqüentemente a criança nascida de uma escrava tinha por pai "um português - digo etnicamente, não civilmente - do melhor sangue" (Freyre apud PallaresBurke, 2005, p.266). No momento da tese, como o atestam também seus artigos publicados nos jornais de Pernambuco, Freyre figurava entre os partidários da doutrina do "embranquecimento da raça" por meio da chegada em massa de imigrantes europeus, única solução a impedir que o Brasil não tivesse acesso aos benefícios da civilização.

Se ele freqüentou os ensinamentos de Franz Boas de 1921 a 1922, a incorporação de seu ponto de vista e a utilização de seus instrumentos de pensamento, para compreender os fundamentos e os efeitos da mestiçagem no Brasil, só tornaram-se incontestáveis nas obras dos anos 1930. Por ocasião de uma nova viagem aos Estados Unidos em 1926, durante a qual ele teve a oportunidade de visitar o “Old South" (Virginia e Maryland), a semelhança entre essa região e o Nordeste do Brasil é evocada em artigos destinados à imprensa num tom nostálgico do perfil aristocrático dessas duas sociedades. Seu antigo colega da Universidade de Columbia, F. Simkins, tinha escrito um livro sobre Benjamin Ryan Tillman (1847-1918), político que chegou a ocupar os cargos de governador do Estado da Carolina do Sul e senador, um dos mais agressivos partidários da utilização de violência contra os negros para garantir a supremacia dos brancos. Gilberto Freyre retomou por sua conta a descrição elogiosa de Tillman feita pelo seu antigo colega, sublinhando especialmente o período da violenta repressão após a Guerra de Secessão como um momento em que graças a Tillman "a democracia branca sabe como exercer o controle da política do Estado, e foram-lhe dados meios pelos quais a possibilidade de um retorno da democracia negra ao poder se tornou muito remota" (Simkins apud Pallares-Burke, 2005, p.311). Gilberto Freyre chega mesmo a propor a seus leitores que Tillman torne-se um modelo dos atributos de um líder político capaz de unificar os senhores de engenho nordestinos decadentes e restaurar seu antigo poder (Pallares-Burke, 2005, p.312).

É interessante assinalar que os períodos no exterior não eram percebidos por Freyre nem por sua família como relacionados estritamente à aquisição de conhecimentos literários ou científicos e à sua certificação mediante diplomas universitários; eles inscreviam-se perfeitamente na linhagem dessas viagens aristocráticas que visavam dotar o jovem descendente de horizontes sociais e culturais mais vastos e dar-lhe oportunidade para constituir um círculo de relações mobilizáveis ao longo de sua vida. Ao reduzir seus estudos nos Estados Unidos ao nível de mestrado, Freyre colocou-se em posição muito vantajosa em relação à 
sua geração de universitários brasileiros, mas em situação precária em relação à competição internacional pelas carreiras intelectuais. Seu retorno ao Brasil começou primeiro por uma viagem à Europa entre agosto de 1922 e março de 1923, para conhecer a França, a Alemanha, a Inglaterra e Portugal. Sua freqüência a instituições acadêmicas e bibliotecas nesse complemento de viagem instrutiva não foi marcada por preocupações de adquirir novos títulos certificando suas novas competências.

Pallares-Burke chama a atenção sobre a passagem pela Universidade de Oxford e o significado profundo que ela teve na existência de Freyre. Ele estabeleceu relações de amizade com um estudante do seletíssimo St. Johns Collège, Linwood Sleigh (1902-1965), período que lhe deixou uma lembrança inesquecível, como testemunhou mais tarde o escritor nordestino José Lins do Rego; relação homossexual assumida, descrita mais tarde como "lírico, além de sensual" (Freyre apud Pallares-Burke, 2005, p.124). Um poema ilustrado com desenhos eróticos faz parte da biblioteca de Gilberto Freyre no Recife, e em sua autobiografia datada dos anos 1950 ele retorna a essa experiência apesar dos chamados à ordem de seu editor. Esse "desvio" das normas rígidas do patriarcalismo brasileiro, como o próprio Freyre classificava seu comportamento, pode sem dúvida fornecer uma chave importante para compreender a objetivação posterior das relações entre senhores e escravos focalizada sobre a sexualidade. A preocupação explícita de Gilberto Freyre de analisar "a psicologia íntima dos brasileiros", enfatizando principalmente a marca das grandes plantações açucareiras fundadas sobre a escravidão das populações africa- nas, pode assim encontrar um elemento de explicação nessa dupla condição de herdeiro da aristocracia dos senhores de engenho e de indivíduo em aberta oposição às normas morais que deveriam regrar os comportamentos. Objetivar os mecanismos sociais do patriarcalismo escravagista no Brasil (as relações patriarcas brancos/mulheres brancas, negras, ameríndias, mestiças; adolescente branco/adolescente negro ou mestiço; mulheres brancas/mulheres negras ameríndias ou mestiças; crianças geradas pelo senhor branco, de seu casamento com uma esposa branca/crianças geradas por outras uniões) podia significar também conceder-se uma chance de mostrar que sua própria experiência pessoal inscreviase em um universo de comportamentos regulares em que entre o "céu" das normas afixadas e a "terra" das práticas observáveis "havia muito mais do que a nossa vã filosofia poderia sonhar" (para guardar a referência aos clássicos da literatura inglesa). Maria Lucia PallaresBurke analisa todos os indícios dessa experiência em Oxford, tendo o cuidado de mostrar como essa forma de amizade entre jovens estudantes era corrente nas seletas "public schools" inglesas e na Universidade de Oxford, sendo mesmo objeto de justificativas estetizantes por meio de referências à Grécia Antiga, a exemplo da defesa de Oscar Wilde, discípulo de Walter Pater, na ocasião de seu processo (Pallares-Burke, 2005, p.120-39). O título escolhido por Pallares-Burke Gilberto Freyre: um vitoriano dos trópicos, assim como a foto dos estudantes de Oxford na capa mostram que a historiadora deseja sublinhar a antinomia entre a moral puritana e o comportamento fora da norma dos escritores como uma pista das mais significativas para a compreen- 


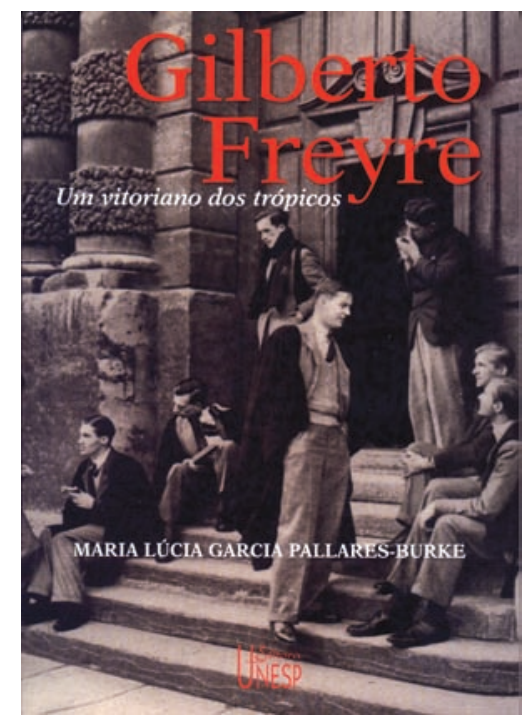

PALLARES-BURKE, M. L. G. Gilberto Freyre: um vitoriano dos trópicos. São Paulo: Editora Unesp, 2005. 486p.

são da trajetória intelectual do escritor do Recife e do alcance de sua obra.

Mas uma qualidade suplementar do trabalho de Pallares-Burke é de nunca reduzir seu modelo explicativo a um único fator, por mais importante e original que seja. Contrariamente às idéias recebidas, Pallares-Burke demonstra que diversos perfis de carreira são esboçados por Gilberto Freyre na sua volta ao Brasil, e que mesmo sua instalação definitiva em Recife não ocorreu sem hesitações, sobretudo após convites de intelectuais de São Paulo. Finalmente, em 1926, Gilberto Freyre aceitou o convite do governador de Pernambuco, Estácio Coimbra, para tornar-se seu principal auxiliar. Esse cargo abria-lhe as portas de uma carreira política de alcance nacional, mas implicava o_adiamento dos projetos literários. As cartas dos seus amigos de Recife e dos antigos colegas da Colúmbia mostram que eles consideravam-no perdido para o mundo propriamente intelectual. Portanto, foi a Revolução de 1930, co- mandada por Vargas, que, ao provocar a destituição de Estácio Coimbra do poder, desacreditou todo o capital político acumulado no círculo imediato das elites da "Velha República" e interrompeu subitamente a carreira política de Freyre. Uma nova viagem à Europa e aos Estados Unidos, no início dos anos 1930, permitiu redigir Casa grande es senzala e fundar a notoriedade de seu autor. Analisando as diversas possibilidades de carreira consideradas por Freyre (escritor ou universitário no mundo anglo-saxão, jornalista no Brasil, político, sociólogo universitário), Pallares-Burke restitui toda a dimensão dos esforços de Gilberto Freyre nos anos 1930-1940 para conferir um novo estatuto à condição de intelectual no Brasil, e torna inteiramente compreensível a enigmática frase de abertura do prefácio da primeira edição de 1933 , em geral descartada pela crítica do contra: "Em outubro de 1930 ocorreu-me a aventura do exílio. Levou-me primeiro à Bahia, depois a Portugal, com escala pela África" (Freyre, 2005, p.29).

O livro de Pallares-Burke, ao inscrever-se na linha dos questionamentos abertos pelos estudos de história da leitura de Roger Chartier e de Robert Danton, e também pela problemática proposta por Pierre Bourdieu sobre o campo intelectual (Pallares-Burke, 2005, p.19), demonstra perfeitamente como a reconstituição dos modos de socialização e da formação intelectual de todo escritor contribui para uma melhor compreensão de todas as afirmações presentes desde a primeira linha das publicações, tornando caducos todos os falsos debates entre análises internas e externas. A nova perspectiva inaugurada por Gilberto Freyre para compreender a posteridade da escravatura no Novo Mundo, já que 
a hierarquia precedente inscreveu-se nos corpos dos indivíduos e nas classificações que estigmatizam ou valorizam o corpo mestiço, exige que nos interroguemos sobre os modos de exercício da sexualidade e sobre as formas de transmissão da condição do genitor, assim como da mãe, às crianças. Observação de um etnólogo: aquele que chama atenção sobre a poligamia dos patriarcas brancos no alto do espaço social pressupõe necessariamente uma alta taxa de celibato nas camadas estigmatizadas e desapropriadas, como aquelas dos descendentes de escravos. Mais um vasto campo de investigações empíricas que sinalizam a pertinência do eixo das pesquisas sobre a história comparada da escravidão moderna (Brasil, Estados Unidos, Antilhas, Cuba), encaminhadas na Escola de Estudos Avançados em Ciências Sociais (EHESS), que poderão renovar nossa compreensão dos mecanismos do parentesco e da filiação nas antigas regiões de plantação de produtos tropicais...

\section{Referência bibliográficas}

FREYRE, G. Maîtres et esclaves (Casa grande \& senzala). 2.ed. Paris: Gallimard, 1952.

Casa grande \& senzala: formação da família brasileira sob o regime da economia patriarcal. 50.ed. revista. São Paulo: Global, 2005.

\footnotetext{
Afrânio Garcia é maître de conférences na Ècole de Hautes Études et Sciences Sociales (EHESS) de Paris e co-diretor do Centro de Pesquisas sobre o Brasil Contemporâneo (CRBC/EHESS).

Tradução de René Lenard. O original em francês encontra-se à disposição do leitor no IEA-USP para eventual consulta.
} 